\title{
VIGENCIA DEL BEATUS ILLE EN LA POESÍA ESPAÑOLA DEL SIGLO XX: REESCRITURAS DEL TÓPICO EN JAIME GIL DE BIEDMA, LUIS ANTONIO DE VILLENA Y ERIKA MARTÍNEZ
}

Dorde Cuvardic García

\section{(c) $(7) \Theta$}

Doi: https://doi.org/10.15517/rfl.v46iExt..43578

URL: https://revistas.ucr.ac.cr/index.php/filyling/index 



\title{
VIGENCIA DEL BEATUS ILLE EN LA POESÍA ESPAÑOLA DEL SIGLO XX: REESCRITURAS DEL TÓPICO EN JAIME GIL DE BIEDMA, LUIS ANTONIO DE VILLENA Y ERIKA MARTÍNEZ
}

\author{
PRESENT-DAY RELEVANCE OF THE BEATUS ILLE TOPOS IN \\ 20TH CENTURY SPANISH POETRY: REWRITES BY \\ JAIME GIL DE BIEDMA, LUIS ANTONIO DE VILLENA \\ AND ERIKA MARTÍNEZ
}

\section{Dorde Cuvardic García}

\begin{abstract}
RESUMEN
El Beatus ille, desde su formulación por Horacio, es un tópico de larga duración que ha pasado por diversas metamorfosis. Ha evolucionado con una invariante semántica, en su núcleo, y con diversas variantes, vigentes en cada época. Además de realizar un recorrido histórico por este tópico en la literatura occidental, el objetivo del presente artículo es analizar e interpretar diversos ejemplos de reescritura del Beatus ille en la poesía española del siglo XX, en particular "De Vita Beata" (Poemas póstumos, 1968), de Jaime Gil de Biedma, "Un tema de Horacio" (Hymnica, 1975) de Luis Antonio de Villena y "Beata illa" (Color carne, 2009), de Erika Martínez.

Palabras clave: tópico; topoi; Beatus ille; poesía española del siglo XX; ironía.
\end{abstract}

\begin{abstract}
The topic Beatus ille, since its formulation by the Roman poet Horace, has a long tradition in Western literature with many variations as it evolves through the ages, always retaining its semantic core. This paper aims to conduct a historical overview of this topic, as well as to analyze and interpret several examples of the modernization of this topoi, in 20th century Spanish poetry, notably "De Vita Beata" (Poemas póstumos, 1968), by Jaime Gil de Biedma, "Un tema de Horacio" (Hymnica, 1975), by Luis Antonio de Villena, and "Beata illa" (Color carne, 2009), by Erika Martínez.

Keywords: topic; topoi; Beatus ille; XX century Spanish poetry; irony.
\end{abstract}

Dr. Dorde Cuvardic García. Profesor de la Escuela de Filología, Lingüística y Literatura. Universidad de Costa Rica. Costa Rica. Correo electrónico: dcuvardic@yahoo.es 


\section{Introducción ${ }^{1}$}

El presente artículo procura destacar la actualidad del tópico del Beatus ille en la cultura contemporánea y, particularmente, en la poesía española de las últimas décadas (recordando que la literatura refracta las preocupaciones de una sociedad). Este es uno de los tópicos de más larga duración. Como cualquier topoi -ocurre lo mismo con los símbolos-, cuenta con un plano invariante y otro variante, es decir, con un núcleo semántico, resistente al paso de las épocas históricas, y con un significado periférico, expresión de los intereses de cada momento. El plano o significado variante es el que permite la evolución del tópico a lo largo de la historia de la literatura occidental y su constante actualización. En este sentido, el tópico 'menosprecio de corte y alabanza de aldea' es la modalidad que adoptó el Beatus ille durante el Renacimiento.

Los temas y los tópicos se pueden clasificar por su vigencia temporal: de corta, mediana o larga duración. Explica Claudio Guillén (2005, p. 255) que "suelen connotar tradiciones perdurables, recuerdos prestigiosos, longues durées" (las cursivas son del texto). Algunos han pervivido en Occidente desde hace más de dos milenios. Por su vigencia diacrónica se acercan a los verdaderos símbolos, cuyo origen, como señala Lotman (2000, p. 135), en su núcleo semántico, se puede discernir hasta el inicio de las culturas.

La historia de la literatura se encuentra estrechamente ligada al estudio de los tópicos (Curtius, 1976, pp. 128-159; Guillén, 2005, p. 255; López Martínez, 2007, p. 32). Aun siendo uno de los más importantes, la evolución histórica del Beatus ille no fue rastreada por E. R. Curtius en su célebre Literatura europea y Edad Media Latina (1955 / 1976), tal vez porque no estuvo vigente en esta última época (es decir, no fue cultivado con asiduidad); recordemos que este investigador alemán se ocupó sobre todo de aquellos tópicos que, habiendo surgido en la Antigüedad grecolatina, pervivieron en la literatura latina de la Edad Media, hasta eclosionar en el Renacimiento.

Un tópico supone la expresión de una temática -codificada por una tradición cultural- que aporta clichés y diseños retóricos, lingüísticos, morfosintácticos y estructurales automatizados. Aluden a sentimientos, emociones o situaciones humanas universales. Y tengamos presente, con Aristóteles, que la literatura se encarga de representar lo universal, es decir, las constantes del comportamiento y de los sentimientos humanos. Aunque las palabras empleadas cambien de escritor en escritor y de periodo cultural en periodo cultural, la idea expresiva, el núcleo o la invariante semántica connotativa que el enunciador quiere comunicar a través del tópico tiene carácter fijo. Y este núcleo se puede organizar en muchos casos, para fines de estudio, como una analogía, como una comparación, como un contraste o contraposición (implícita o explícita), como una metáfora, como una imagen poética o como un enunciado solidificado. Concordamos con López Martínez (2007, p. 32), quien señala que el contenido del tópico se produce desde la incorporación de palabras clave. Estas últimas aluden a su núcleo semántico invariante. Su estudio se ha constituido en un campo independiente, muy importante en la tríada teoría-crítica-historia literaria.

Los tópicos, tanto al acuñarse como al utilizarse posteriormente, presentan unas coordenadas geográficas, históricas y contextuales que remiten a la sociedad en la que surgen.

1 Agradezco a Maricela Cerdas la participación que ha tenido en este artículo con comentarios, ideas, fuentes y argumentos. 
Como declara E. R. Curtius, "el estilo en que se expresan [...] está siempre condicionado históricamente" (1976, p. 127). Al crear un modelo de mundo (literario), constituyen el testimonio de una forma de entender la vida. Responden al modelo o visión de mundo imperante en cierta época. Señalan Cuvardic y Pérez Parejo (2019, p. 86) que los tópicos de la 'danza de la muerte' y de la 'batalla de amor' remiten a los miedos y la forma de vida de la Edad Media, con una moral cristiana basada en el temor de Dios, el dogma, la resignación, la rígida estructura estamental, la promoción de valores como la honra y el honor y una comprensión bélica de las relaciones entre los individuos y entre los Estados. Nuestro propósito, en el presente artículo, radica en responder a la pregunta -algo que haremos en las conclusiones del presente estudio- sobre los motivos que explican la relativa frecuencia del tópico del Beatus ille en las últimas generaciones poéticas españolas.

\section{Origen del tópico del Beatus ille: el "Épodo II" de Horario}

Escritos entre el 41 y el 30 d. C., en los inicios de la carrera poética de Horacio, los Épodos (1984 versión) $)^{2}$ son composiciones cortas que se enmarcan en la tradición de la poesía yámbica griega, caracterizada por su contenido injurioso y su tono agresivo. El mismo autor, en sus Epístolas (1984 versión), reconoce la inspiración del yambógrafo griego Arquíloco 3 . Adicionalmente, la obra horaciana se emparenta con la sátira romana y con Lucilio, este último como el representante más influyente para Horacio.

El "Épodo II", de Épodos (1984 versión), como modelo clásico de alabanza de la vida campestre, ha sido ampliamente estudiado. En él se establece al inicio un contraste entre la apacible existencia de un campesino frente a la de un soldado, un marinero y un habitante de la ciudad. Se prosigue con un recuento de las labores típicas del campo, según las estaciones del año, y se mencionan los simples placeres que proporciona este estilo de vida, preferible a cualquier otro, según la voz enunciativa de esta primera parte (versos 1-67, que se encuentran entre comillas). Termina el poema (versos 68-70) con el recurso del aprosdóketon ${ }^{4}$ : se revela que todo lo anterior fue dicho por Alfio, un usurero, que no tiene ninguna intención de abrazar la vida campesina.

Este final provoca, en cierta medida, la ridiculización de este género de vida: nada en el poema nos lleva a creer que Alfio, usurero que seguramente habita en la ciudad y no podría ejercer su oficio en el campo, tenga alguna intención de adoptar ese modo de vivir; más bien, por su mismo carácter lo desprecia, razón por la que se piensa que su elogio debe haber sido emitido con intención irónica. Por una parte, se puede considerar que Horacio, humorísticamente, busca con este final inesperado que el lector no tome tan en serio dicho elogio y, por otra, que el autor oriente su burla hacia el usurero, quien al inicio profiere palabras elogiosas sobre el sistema de vida campesino, pero que al final del poema deja atrás el campo y tiene su mente ocupada, en el presente de la enunciación, en hacer rendir mejor su dinero. En otras palabras, la primera lectura destaca la crítica de la vida campesina, que siempre ha experimentado un elogio

2 La denominación de estos poemas hace referencia a su forma métrica: un épodo es un verso más corto que sigue a uno más largo, con el cual forma un dístico (Conte, 1994, p. 293).

3 "Yo fui el primero en mostrar al Lacio los yambos de Paros, siguiendo los metros y los ánimos de Arquíloco, no sus asuntos ni las palabras con que acosaba a Licambes" (Epíst. I, 1984 versión, vv. 23-25).

4 Es el final inesperado, la aparición de algo para lo que el lector no estaba preparado y que produce un efecto cómico. 
hiperbólico en el pensamiento literario occidental, mientras que la segunda lectura emprende una crítica de la usura. En todo caso, para Torre (1999, p. 2), este poema:

mediante una pincelada irónica en los versos finales, viene a ser también una recia censura contra la actitud vital de aquellos hombres que nunca están contentos con su suerte. No hay que olvidar que la mempsimoiría, la 'queja contra el destino', es efectivamente uno de los temas centrales en la obra de Horacio (las cursivas son del texto).

Desde esta última lectura, el poema realizaría una crítica de aquellas personas que nunca están satisfechas con el estilo de vida que llevan, ya sea el urbano (usura, corrupción, pero con mayor bienestar material) o el rural (simple, pero aburrido).

Cabe señalar que el tono irónico de quien enuncia no logra desvirtuar la alabanza del campo. A pesar de estar en boca de Alfio, el idílico retrato horaciano de la plácida existencia lejos de la ciudad se convirtió en modelo literario de la beatitud que puede ofrecer la vida campesina. Como vemos, se trata de un poema ambiguo (y formulado como tal por la intención autoral horaciana) que admite simultáneamente diversas lecturas. Y el principal soporte expresivo de esta ambigüedad es el sistema enunciativo empleado en el poema. Las interpretaciones son innumerables, resumidas en Albornoz (2014), pero todas ellas hablan de la ambigüedad del poema.

En el número 2 de la Revista de Filología y Lingüística de la Universidad de Costa Rica, Miranda Hevia (1975, pp. 81-91) realizó un análisis estilístico y enunciativo del poema. Según esta investigadora, en el épodo se identifican dos voces enunciativas ${ }^{5}$. En primera instancia, la voz de Alfio se encarga de describir un mundo hipotético positivo, la vida campestre, negación de la realidad en la que vive al enunciar su discurso, la vida de un usurero. Por medio de la descripción de este ideal, estas actividades pasan a ser más reales que las circunstancias en las que vive el mismo Alfio. La realidad poética negativa está introducida por la partícula 'ne', mientras que el ideal poético lo está por la partícula 'aut', mundo idealizado de la vida campestre, caracterizado por actividades agrícolas y recreativas como la caza y el descanso, y definido como un lugar ameno, como un 'locus amoenus'. Se distingue una voz lírica que enuncia (Alfio) y un objeto lírico enunciado (Beatus ille qui... Lares). La voz de Alfio, cuya enunciación ocupa las 33 primeras líneas del poema, queda a su vez incorporada en una voz que la envuelve, la de un yo enunciativo que aparece en las últimas dos estrofas y que nombra al usurero desde la tercera persona. La realidad circunstancial negativa descrita en la que vive el usurero es la misma en la que se encuentra la voz enunciativa. Esta última cumple la siguiente función: que la instancia lectora aprecie la diferencia existente entre la realidad poética negativa, las circunstancias en las que vive Alfio, y la realidad positiva o hipotética que expone este último en su discurso. Esta disonancia es la que produce la ironía, que Miranda Hevia (1975) considera como principio estructurante del poema: la ironía, como procedimiento retórico y discursivo, está fundamentada en el principio de la contradicción. La realidad positiva hipotética queda configurada en el dictus enunciado por Alfio, mientras que el modus parte de la realidad negativa circunstancial enunciada por el yo lírico.

La interrelación entre ambas voces es explicada con claridad por Miranda Hevia (1975). El yo lírico distanciado enuncia el discurso de Alfio, quien se convierte así en el objeto o tema de su discurso. El yo lírico no solo es épico (en términos enunciativos, al relatar otro discurso, el del usurero), sino también analítico, al calificar la enunciación de Alfio. Su presencia

5 A partir de este momento se resume la propuesta de esta crítica literaria. 
es indispensable. Sin esta última voz, que aparece al final del poema, no tendría lugar la enunciación irónica y no serían necesarias las 33 primeras estrofas, concernientes al elogio de la vida retirada.

Las reescrituras posteriores del tópico del Beatus ille han llamado la atención de la crítica. Ramajo Caño (1994) analiza la "Oda a la vida retirada" de Fray Luis de León, la más conocida reescritura (entre todas las realizadas en la literatura española) y la estudia en dos de los atributos que comparte con su modelo horaciano: la semántica del elogio de la vida retirada y su carácter proemial. Por su parte, Carrasco (1993) estudia las variantes y las invariantes de lo que denomina modelo textual (es decir, tópico) del Beatus ille en la comedia de labradores y en el poema barroco de las Soledades, de Góngora. Febles (2016) analiza su empleo, que equipara al de menosprecio de corte y alabanza de aldea, en la poesía del cubano Agustín Acosta, en particular La zafra (1926). Barrenechea (2017), a su vez, se acerca a la inversión del Beatus Ille en La ciudad ausente (1992), del argentino Ricardo Piglia.

\section{Breve recorrido por la historia del tópico del Beatus ille en la literatura occidental}

Cabe preguntarse si el Beatus ille es un universal lírico, si se puede encontrar como tópico en otras culturas, más allá de la cultura occidental. Investigaciones que se realicen desde el ámbito de la literatura comparada podrían responder en el futuro a esta pregunta.

En la Antigüedad, además de Horacio, este tópico fue desarrollado por Virgilio, al final del Libro II de las Geórgicas (2010 versión, versos 458 y siguientes). Tras un declive en la Edad Media, vivió un auge durante el Renacimiento y el Barroco. Dos revisiones del tópico en estas dos épocas la ofrecen Agrait (1971), y Cacho Casal (2003). Se emplea en La comedieta de Ponça (1444), del Marqués de Santillana: “ßBenditos aquellos que con el açada / sustentan sus vidas e viven contentos / e de quando en quando conosçen morada / e sufren paçientes las lluvias e vientos! / Ca éstos non temen los sus movimientos, / nin saben las cosas del tiempo pasado, / nin de las presentas se fazen cuidado, / nin las venideras do han nasçimientos" (1961 versión, p. 846). Vivir en el momento presente sin las preocupaciones de las posesiones es el núcleo semántico de esta última estrofa. Pero el ejemplo más famoso de todos es "Canción a la vida solitaria”, de Fray Luis de León: “QQué descansada vida / la del que huye el mundanal ruido / y sigue la escondida / senda, por donde han ido / los pocos sabios que en el mundo han sido [...]!” (1999 versión, p. 124). La renuncia a los conflictos sociales se eleva como el principio rector de estos primeros versos. También recurre a este tópico Garcilaso de la Vega, en su "Égloga II" (1533-1534), por boca del pastor Salicio: “¿Cuán bienaventurado / aquel puede llamarse / que con la dulce soledad s'ebraza, / y vive descuidado / y lejos d'empacharse / en lo que al alma impide y embaraza! / No ve la llena plaza / ni la soberbia puerta / de los grandes señores, / ni los aduladores / a quien el hambre del favor despierta; / no le será forzoso / rogar, fingir, temer y estar quejoso" (de la Vega, 2001 versión, p. 150). En esta estrofa, la sociedad queda perfilada como un espacio lleno de imposturas, máscaras e hipocresía. Por su parte, en Lope de Vega se aprecia el tópico en la novela Los pastores de Belén: prosas y versos divinos (1612 / 2010): “Dichoso el que no mira / del altivo señor las altas casas / ni de mirar se admira / fuertes columnas oprimiendo basas / en las soberbias puertas / a la lisonja eternamente abiertas! Los altos frontispicios / con el noble blasón de sus pasados / los bélicos oficios / de timbres y banderas coronados / desprecia, y tiene en menos / que en el campo los 
olmos de hojas llanos". También lo empleó este escritor en el marco de una canción enunciada por un grupo de músicos en la comedia El villano en su rincón (1617 / 1987).

Quisiera destacar el uso -en casi todos estos ejemplos renacentistas y barrocos- de la exclamación -que está ausente en el modelo horaciano-, un recurso retórico que solo se hará omnipresente en la poesía lírica romántica y su yo exaltado. La exclamación tiene en los casos mencionados connotaciones desiderativas: la felicidad que se atribuye a aquel que goza de una vida retirada en el campo es un deseo que el yo lírico quisiera para sí mismo.

Durante el Renacimiento también podemos identificar el tópico del 'Menosprecio de corte y alabanza de aldea', en la obra del mismo nombre de Antonio de Guevara (1539 / 1984), que adopta la forma de tratado ensayístico. Ante esto, se pueden plantear las siguientes interrogantes: ¿el Beatus ille y el 'Menosprecio de Corte y Alabanza de Aldea' tienen el mismo contenido semántico?; ¿cuentan entre sí con unos límites semánticos claros o uno de ellos está subsumido en el otro? Si queremos responder a estas preguntas, podemos concluir que el tópico del 'Menosprecio de corte y alabanza de aldea' forma parte del tópico del Beatus ille. Se trata de una variante senequista y cristiana de este último. Concuerdo con Rallo (1984, p. 68), quien en su estudio introductorio de la obra de Guevara (1539 / 1984) señala que "[e]n confluencia con una literatura religiosa de carácter ascético (contemptus mundi), Guevara le presta la originalidad de un planteamiento para un aquí y un ahora, fundiendo en un sistema contrastivo el vituperio del mundo y la alabanza del campo, y ofreciéndolo desde la perspectiva del cortesano experimentado" (las cursivas son del texto). Más que de un rechazo de la corrupción moral de la ciudad o de la vida en sociedad, se trata de un repudio específico de la vida cortesana. Recordemos, en este sentido, las advertencias dirigidas contra la hipocresía de este estilo de vida en manuales de educación para cortesanos como El príncipe (1532), de Nicolás Maquiavelo, o El Cortesano (1528), de Baltasar de Castiglione. Además, su contenido se canaliza más explícitamente como una antítesis, como una dicotomía (alabanza de la vida aldeana, repudio de la vida cortesana), mientras que el Beatus ille se expresa casi exclusivamente desde la alabanza de la vida aldeana y la crítica de la inmoralidad urbana, y no exactamente de la cortesana, que se encuentra implícita.

Posterior al declive de la cultura del Clasicismo, la presencia del Beatus ille cae en letargo. Si pervive, lo hará a través de actualizaciones, no a través de la práctica clasicista de la imitatio. Así ocurre en formato narrativo en la novela Far from the madding crowd, Lejos del mundanal ruido (1874 / 2002), del inglés Thomas Hardy, que ha contado con numerosas adaptaciones cinematográficas. Asimismo, el rechazo de la urbe y la atracción de la vida natural o campestre forma parte de una importante corriente de pensamiento de la cultura norteamericana, como se puede apreciar en Walden (1854), de Henry David Thoreau. Se trata de un imaginario cultural estadounidense -revitalizado en la sociedad postmoderna- que encuentra una crítica sutilmente irónica en la película La aldea (The Village), 2004, de M. Night Shyamalan. Nos referimos a la tradición 'pastoral' de este espacio cultural, es decir, al rechazo de la cultura urbana, claramente asociada a la decadente sociedad europea y a la pretensión de encontrar en América -en realidad, poseer- un espacio rural en el que se puedan cumplir todos aquellos ideales utópicos individualistas (libertad) que no pudieron alcanzarse previamente, en un mundo lastrado por la tradición. Es una visión de mundo muy semejante al sentimentalismo prerromántico (de J. J. Rousseau) y su defensa de la vida en la naturaleza. En última instancia, en el elogio de la vida campesina podemos identificar el modo de sentir idílico -enunciado por Friedrich Schiller en Sobre poesía ingenua y sentimental (1795 / 1995)-, es 
decir, la armonía entre el ideal (sencillez y ausencia de problemas) y la realidad (valores que se asocian a la vida campestre).

\section{La actualización del tópico del Beatus ille en la literatura contemporánea española}

El Beatus ille ha sido actualizado en la literatura española de los últimos cincuenta años, principalmente en el discurso poético. Como excepción, una contribución relevante de las reescrituras se ha dado a través de la prosa, en concreto en la primera novela publicada por Antonio Muñoz Molina, Beatus ille (1986), que cuenta con numerosos análisis, entre ellos Cuvardic (1998), Latorre Madrid (2003) y González Arce (2005). Creo que dos razones pudieron haber decidido al escritor jienense a adoptar este título, que en el presente caso es un intertexto programador del proceso interpretativo de la instancia lectora.

En primer lugar, a nivel enunciativo se presenta una similitud entre el épodo de Horacio y la novela del escritor andaluz. En el poema de Horacio, la voz enunciativa marco - procedente de Alfio- se 'revela' al final como el origen del discurso expresado en los versos previos. Asimismo, en la novela de Muñoz Molina se presenta el mismo procedimiento. Aunque la instancia lectora interpreta en un principio al narrador como heterodiegético, se revela finalmente como homodiegético, identificado como Jacinto Solana, un supuesto autor olvidado de la Generación del 27, quien ha estado relatando todos los acontecimientos contenidos en la novela. Jacinto Solana oculta durante la mayor parte de su relato su papel de voz narradora. Al ocultarse como narrador, puede relatar, analizar, seleccionar, tergiversar, inventar u omitir los acontecimientos. Supera los obstáculos de la escritura testimonial. Jacinto Solana, como narrador, emplea una focalización cero: tiene acceso a los pensamientos de los personajes y relata acontecimientos que no ha presenciado. El narrador inventa la realidad en la que vive: muchos acontecimientos narrados no han sido percibidos 'directamente' por esta figura.

Pero el paralelismo enunciativo, en segundo lugar, no es la única semejanza entre el épodo de Horacio y la novela de Muñoz Molina, y considero que no es la principal razón por la que el escritor jienense eligió las dos primeras palabras del poema del autor latino como título de su relato. Alude al retiro, alejado del compromiso político, de Jacinto Solana, quien encuentra en la ciudad andaluza de Mágina - una especie de 'ciudad muerta' provinciana-, un perfecto escondite para escapar de las autoridades franquistas durante largas décadas de exilio interno.

Como ya queda dicho, el Beatus ille se ha actualizado en la literatura española de las últimas décadas desde el discurso poético. Los textos que analizaremos son "De Vita Beata" $\left(1968^{6}\right)$, de Jaime Gil de Biedma; "Un tema de Horacio", originalmente publicado en Hymnica (1975), de Luis Antonio de Villena, y posteriormente incorporado en su Poesía. 1970-1982 (1983) y en Alejandrías [Antología, 1970-2003] (2004); y "Beata illa" (Color carne, 2009), de Erika Martínez ${ }^{7}$ Se podría pensar en un inicio que el conocido poema de Jorge Guillén "Beato

$6 \quad$ Originalmente publicado en Poemas póstumos (1968); además, este poema cierra Las personas del verbo (1975 / 1991). En la bibliografía del presente artículo se opta por incluir únicamente la referencia de esta última obra.

7 Asimismo, en la cultura española contemporánea, el grupo de música El último de la fila también ha actualizado el tópico que nos ocupa con "Beatus Ille", de su disco Nuevo pequeño catálogo de seres y estares (1990), tema instrumental que, por esta razón, carece de letra. 
Sillón" (Cántico, 1975, p. 79), responde al tópico que ocupa el centro de atención del presente artículo, pero expresa con mayor pertinencia el tópico del aurea mediocritas, por lo que será excluido del presente análisis.

Desde la generación de los llamados novísimos - con su acendrado culturalismo- se ha producido una eclosión de operaciones intertextuales en la poesía española. Y una de estas operaciones es la actualización irónica de los tópicos clásicos. Prieto de Paula (1996, pp. 267269) sostiene que, mientras algunas épocas literarias - de carácter innovador, liberadas de la tradición- se caracterizan por la creación de estructuras antropológicas, de modelos abreviados de la realidad, de modelos temáticos -léase, por ejemplo, los topoi- (momentos 'creadores'), otros momentos históricos, en cambio, presencian la simple reproducción de estos estereotipos, alejándose de la originalidad y plegándose al prestigio de la tradición (momentos 'recolectores'). Las últimas generaciones poéticas, de carácter culturalista, contra lo que podría pensarse en un primer momento, constituyen una expresión del segundo tipo, según Prieto de Paula. Pero esto no significa que renuncien a la originalidad. De hecho, proceden a la actualización (muchas veces, a la reescritura irónica) de estos universales temáticos. Es lo que sucede, por ejemplo, con el tópico del Beatus ille. A continuación, se analizarán e interpretarán los poemas mencionados.

\section{Primera coda: la renuncia al compromiso social del intelectual en "De Vita Beata" (1968), de Jaime Gil de Biedma}

"De Vita Beata" es uno de los más conocidos poemas de Jaime Gil de Biedma. Procede de Poemas póstumos (1968), y cierra Las personas del verbo (1975 / 1991), que ofrece el conjunto de su obra. Este poeta catalán forma parte de la llamada "Escuela de Barcelona", a la que pertenecen el editor y escritor Carlos Barral, los poetas José Agustín Goytisolo y Gabriel Ferrater o el crítico literario José María Castellet. El sentimiento de pérdida, las limitaciones de la clase media y la temporalidad son constantes temáticas de su poesía (Debicki, 1997, p. 179). Pérez Parejo (2007, p. 217) considera que este poema contrasta irónicamente "con el resto de su obra, en la que siempre ha dominado la temática urbana”. Desde otras coordenadas, no podemos perder de vista, sin embargo, que Gil de Biedma siempre ha sido un poeta irónico en el tratamiento de sus temas. Es un poema corto que se ofrece a continuación:

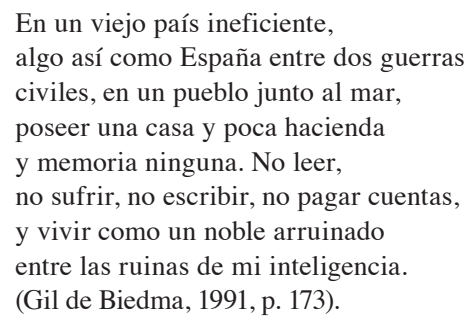

Pérez Parejo (2007, p. 217) sostiene que el poema de Gil de Biedma, "que se enmarca en una tradición ascética aplicada a la vida del siglo XX, plantea los condicionantes que el sujeto lírico postula para llevar a cabo su ideal de vida: retirarse del mundanal ruido, de la burocracia, y dedicar las horas a la contemplación y la meditación". Surge, en este momento, la siguiente pregunta: ¿por qué asume este proyecto? El poema alude a una España subdesarrollada ("país ineficiente'), un espacio sociopolítico que se encuentra en un impasse. El poema fue publicado en 1968, en los últimos estertores de la prolongada dictadura franquista. La contextualización 
temporal de este país en 'algo así como entre dos guerras civiles' es una alusión a las numerosas guerras civiles que asolaron España en el siglo XIX, donde el estado de paz era una excepción y no la regla. Pero el sintagma 'entre dos guerras' nos habla más bien de la semántica de la inercia del inmovilismo sociopolítico. Las guerras civiles representan, por lo general, momentos de sacudida social y el marco temporal que existe entre ambas debe entenderse, más bien, como un interregno en el que no sucede nada, alusión al impasse político y social de la España del franquismo.

Ante un país caracterizado por estos atributos solo cabe el retiro del intelectual y su aceptación del aurea mediocritas, de la dorada mediocridad o término medio. El perfil de la voz enunciativa del poema pertenece a un intelectual en crisis (ha dejado de leer, carece de memoria, su inteligencia se encuentra en ruinas...). La voz enunciativa opta por renunciar al compromiso sociopolítico del intelectual, en momentos -los años sesenta-, en los que Occidente debatía sobre este papel (sobre todo la intelectualidad francesa, comenzando por textos como ¿Qué es la literatura?, 1948 / 1990, de Jean-Paul Sartre).

Con el uso de verbos en infinitivo, la voz lírica opta por ofrecer un breve manual de instrucciones -caracterizadas por la negación de toda volición- que, al final, en el último verbo, se revelan como dirigidas a la propia voz enunciativa. Quance (1987, pp. 306-307) destaca la ausencia del pronombre personal de primera persona ('yo'), reducida a una simple inferencia del lector, mientras que la forma verbal empleada -el infinitivo- sitúa al sujeto fuera de las coordenadas temporales; su actitud hacia el pasado, de cansancio o derrota, radica en negar este último.

Se asume una postura ascética de renuncia a un ideal comprometido del que, con hastío, se distancia el yo enunciativo. La instancia lectora puede actualizar o hacer explícitos los posibles verbos que, implícitos, guían esta enumeración de instrucciones en infinitivo: 'hay que', 'se debe' o 'es preciso' poseer una casa y poca hacienda; no 'se debe' leer, ni sufrir...; no 'se precisa' escribir; 'es irrelevante' pagar cuentas. Pérez Parejo (2007, p. 217) se refiere en este aspecto a "la elisión intencionada de un verbo principal de deseo del que partirían los demás verbos completivos en infinitivo que aparecen en el texto”. Una vez leído el poema, nos damos cuenta de que estas instrucciones responden a un programa de retiro o renuncia de todo compromiso sociopolítico.

También nos interesa destacar que, así como al final del épodo de Horacio se muestra la identidad de la voz enunciativa, oculta a lo largo del poema, en el poema de Gil de Biedma también se procede a ejecutar la misma intención enunciativa: la voz impersonal, objetiva, se revela como subjetiva, originada en un individuo en crisis existencial e intelectual ('entre las ruinas de mi inteligencia'). Si bien responden a una psicología individual, las ideas ofrecidas en los versos precedentes se podrían revelar finalmente como el 'manifiesto' de todo intelectual en crisis que desee sobrevivir a la sinrazón de las absurdas rencillas humanas y de una sociedad y un sistema político en los que no cree.

Es, además, una renuncia voluntaria. Se aprecia en la gradación descendiente 'poseer una casa y poca hacienda / y memoria ninguna'. Es decir, la intención de la voz enunciativa es quedarse con una posesión mínima (una casa) y desprenderse del patrimonio material (poca hacienda) y del sufrimiento de los recuerdos (producido por el hecho de ver cómo el proyecto sociopolítico en el que se cree no ha logrado triunfar), viviendo simplemente en el presente (memoria ninguna). Otros intelectuales han adoptado, con distintas variaciones, un retiro final, después de una época de luchas (por el reconocimiento social de su condición de 
escritores, por la defensa de lo que consideran justo, etc.), como es el caso de Luis de Góngora. En este sentido, creo que debe leerse este poema en términos metaliterarios, como un retiro del intelectual de sus 'obligaciones' en la República de las Letras. Si algún acto de habla predomina en este poema es el de renegar. El intelectual se inocula con la vacuna del olvido. Pérez Parejo (2007, p. 217) llama la atención hacia el hecho de que esta idea de la pérdida de la memoria como liberación ya fue empleada por Pere Gimferrer. Nos referimos, exactamente, a "Si pierdo la memoria, qué pureza", primer verso del poema "Una sola nota musical para Hölderlin" (Arde el mar, 1966 / 2000).

La importancia en la resignificación del tópico estriba en que la voz enunciativa se muestra ante la instancia lectura como un escritor. La contraposición ya no se establece entre la urbe y el espacio rural, sino entre la escritura / compromiso social y su abandono. Pérez Parejo (2007, p. 217) aprecia cierto tono de desidia (en expresiones del tipo 'algo así como'). Pero la renuncia va más allá. En este poema, el Beatus ille ha sido resignificado en clave nihilista. La voz enunciativa busca alejarse de cualquier tipo de compromiso, no solo intelectual (no leer, no escribir) y emotivo (no sufrir ante las injusticias sociales), sino también de las obligaciones cotidianas de la vida rutinaria moderna ('no pagar cuentas').

\section{Segunda coda: frente a la vida postmoderna urbana, el retiro campestre hedonista en "Un tema de Horacio", Hymnica (1975), de Luis Antonio de Villena}

Luis Antonio de Villena pertenece a la Generación de los novísimos, claramente asociada al culturalismo, estética que incorpora la actualización o reescritura de los clásicos. El presente poema se ofrece, desde su título, como una variante del tópico horaciano, como una reescritura o relectura, como una alusión a una tradición literaria. El impreciso programador de lectura del título queda finalmente aclarado en el verso final, que adopta en su tono de máxima, la función de epifonema o recensión de las ideas ofrecidas en los versos anteriores. A continuación, se ofrece el poema:

\footnotetext{
Bajo el aura del duro sol primero y el trino inaugurado de los pájaros, abandonar el hogar tras el almuerzo, en el breve calor que adelanta el verano. No ir, si tenías que ir a lugar convenido, ni entrar a clase, aunque el estudio importe, ni salir hoy a comprar cosas determinadas... Ponerse a caminar, con el amigo cómplice, que huye también la tarde, por la cuesta abajo, hacia la hierba y los pinos, solitarios... Tenderse allí y hablar del duro otoño, ya pasado, mientras invita el sol a retirarse ropa, y molestan los insectos renovados. Y allí dejar pasar las horas insensiblemente, entre calor y vaho de flores, dormitando. Se charlará despacio, y surgirá el silencio. Y si el sexo incomoda alegremente, no habrá sorpresa. Es huésped esperado y cotidiano... Por lo demás, amodorrarse allí, vivir al sol, dejar pasar el tiempo, y olvidarse de todo. Que ya sabes el verso: Dichoso el que de pleitos alejado. (de Villena, 1983, p. 175; 2004, pp. 73-74).
} 
Este poema se presenta, enunciativamente, al igual que en Gil de Biedma, como un manual de instrucciones implícito que el hablante se plantea a sí mismo, como una serie de recomendaciones, como una desiderata que se dirige mediante la utilización del tú autorreflexivo del final ('que ya sabes el verso'). El contexto es el de una primavera todavía muy próxima al invierno (solo recientemente han comenzado a cantar los pájaros), cuando el excesivo calor del verano se encuentra todavía lejano, pero que invita, atemperado, a despojarse de la ropa y a compartir el contacto corporal con otro ser humano. El justo medio del aurea mediocritas se proyecta, asimismo, a las condiciones contextuales: la búsqueda de un clima atemperado también permite el disfrute del placer momentáneo.

En el poema de Gil de Biedma, la actitud que predomina es la de renuncia, en el marco de la ausencia de obligaciones sociales, vinculadas todas ellas a la vida urbana y sus compromisos. También es el caso de Luis Antonio de Villena: 'No ir, si tenías que ir a lugar convenido, / ni entrar a clase, aunque el estudio importe, / ni salir hoy a comprar cosas determinadas'. Estos tres versos guardan la misma semántica que el sintagma 'no pagar cuentas' del poema de Gil de Biedma. No cumplir con las citas programadas, con las prescripciones de la educación formal ('no entrar a clase, aunque el estudio importe', puede aludir tanto a las obligaciones de un docente como a las de un estudiante), no seguir un estilo de vida consumista... Pero, además, el equilibrio emotivo se logra a partir de la ejecución de actividades cotidianas que no giran alrededor de la esfera laboral, que no están sujetas a la presión del tiempo objetivo del reloj: dar paseos campestres después del almuerzo con un amigo cómplice, tenderse a tomar la siesta al sol, disfrutar de la complicidad de la conversación, del silencio y del sexo -sin ningún compromiso a futuro. Se vive el momento placentero, desde un programa vital epicúreo. En este programa se observa una diferencia con el poema del escritor catalán: en el caso de Villena se aprecia el deseo de practicar un otium que en el caso de Gil de Biedma está cercano al tedio, el nihilismo.

El enunciado "Es huésped esperado y cotidiano...", en relación con el sexo, no es exactamente un caso de aposiopesis o reticencia (es decir, dejar inacabado un enunciado), motivado por una intencionalidad eufemística o atenuadora. Más bien, los puntos suspensivos, en este caso, buscan que la instancia lectora reflexione sobre el punto de vista que la voz enunciativa tiene de la práctica sexual, su carácter cotidiano, irrelevante, nimio. El sexo es necesario, pero el hablante le quita cualquier connotación trascendental. Se trata de vivir en el presente. En estos términos, es un poema epicúreo. Frente a la hiperactividad de las obligaciones de la vida urbana postmoderna (laborales y sociales), se propone su negación en la vida rural.

En el epifonema, la voz enunciativa alude intertextualmente al verso inicial del épodo de Horacio (1984 versión). El verso final -“Que ya sabes el verso: Dichoso el que de pleitos alejado"- está lleno de implicaturas. Cuando se reescribe el verso inicial horaciano Beatus ille qui procul negotiis... en el verso final Dichoso el que de pleitos alejado, el hablante del poema de Villena llega a equiparar la vida social con el conflicto, pero de ínfima categoría: el 'pleito' es cotidiano, irrelevante, un tipo de conflicto de origen irrelevante, pero cuya escalada conduce a posiciones polarizadas.

La voz enunciativa es consciente de reescribir-actualizar- un tópico de larga duración. Implícitamente, se parte del hecho de que la vida urbana -y más que todo la reglamentada, la sujeta a las prescripciones y obligaciones- es fuente de pleitos. Y la ausencia de estos 
últimos, por contrapartida, es fuente de felicidad o, por lo menos, de placidez. La cláusula de la voz enunciativa -"Que ya sabes el verso"- que introduce la reescritura del tópico original, convierte a este último, más bien, en una sentencia o proverbio, en una recomendación para la vida: con el tiempo ha pasado a convertirse en parte de la sabiduría popular.

\section{Tercera coda: la crítica de los enclaves urbanísticos del espacio rural en "Beata illa" (Color carne, 2009), de Erika Martínez}

Erika Martínez (n. Jaén, 1979) es una escritora que, hasta el momento, ha publicado los libros de poemas Color carne (2009), El falso techo (2013) y Chocar con algo (2017) y la colección de aforismos Lenguaraz (2011). Frente al resto de las reescrituras del Beatus ille en la historia literaria española, opta por emplear el lexema "Bendita" en lugar de "Beata" en el primer verso del poema, aunque decide conservar el pronombre demostrativo "aquella". En este caso, designa a un sujeto femenino, en lugar del tradicional sujeto masculino, implícito o explícito en todas las variaciones del tópico.

"Beata illa", procedente su primer poemario (I Premio de Poesía Joven de Radio Nacional de España, 2008), supone la actualización irónica postmoderna de un tópico por sí mismo irónico. En el poema se realiza una crítica mordaz del concepto cultural que podríamos denominar como 'campo urbanizado'. Se desplazan, por lo tanto, los objetos tradicionales del elogio y de la crítica del tópico del Beatus ille. Si en este último la oposición semántica de la que se parte es la crítica de la ciudad y su sociabilidad corrupta (esfera de imposturas, conflictos irrisorios, corrupción, hipocresía), frente a la vida rural (en la que, supuestamente, predominan unas relaciones sociales basadas en la honestidad y en la ausencia de artificio), en el poema de Erika Martínez se opera un desplazamiento de las 'fuerzas semánticas'. En el presente caso, la oposición se da entre el 'espacio rural urbanizado' y el 'espacio rural no urbanizado'. El suburbio no es sino una extensión de la ciudad, de su estilo de vida, sometido a la temporalidad implacable de la planificación horaria, de los trayectos regulares de la casa al trabajo y viceversa. A continuación, se ofrece la primera parte del poema:

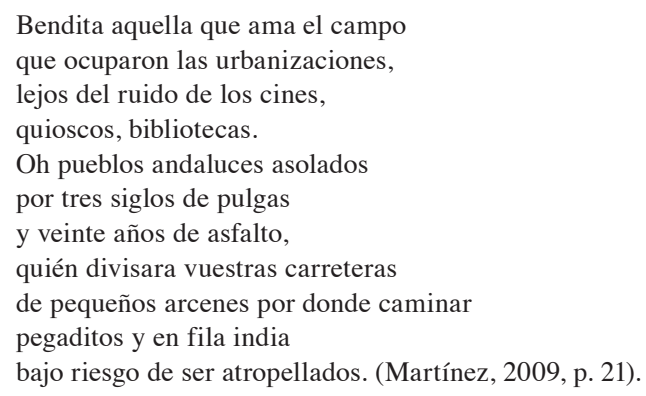

Se emplea una tercera persona genérica, generalizable a todos aquellos individuos seducidos por el estilo de vida de las urbanizaciones. Pero se trata de un elogio irónico. Es una antífrasis: se elogia para criticar. Como ya queda dicho, en lugar de una inversión, se ha operado un desplazamiento semántico del tópico del Beatus ille. En el presente de la enunciación, lo que se valora positivamente es el campo 'antes' de que este último lo ocuparan las 'grandes superficies' comerciales y las urbanizaciones. El espacio con historia de los pueblos ha sido desplazado por 'no lugares' (Augé, 1996) postmodernos. Los primeros cuatro versos 
son expresados por una voz enunciativa irónica que, desde su posición epistemológicamente superior, se apropia del discurso de un sujeto alienado e ignorante que pretende alejarse de un espacio urbano simbolizado por el ruido y que procede a catalogar como negativo -en su incongruencia- el sistema de vida asociado a los cines, los quioscos y las bibliotecas. Se apropia de uno de los lugares comunes que emplea el urbanita -en su autoengaño, convencido por el discurso publicitario- para justificar su mudanza a la periferia de la ciudad. Las familias que se trasladan a las urbanizaciones expresan argumentos que se podrían expresar con 'frases hechas' como la siguiente: 'hemos decidido instalarnos en el campo para alejarnos del tráfico y ruido de la ciudad'. Sin embargo, este sujeto alienado, al mismo tiempo que se aleja del ruido de las calles, lo está haciendo también de la cultura y del ocio asociado al estilo de vida urbano.

En el ámbito de la intención irónica de la voz enunciativa se emplean explícitamente recursos típicos de la retórica del discurso epidíctico ('Bendita', o la exclamación retórica 'Oh') con el propósito de criticar, implícitamente, las 'islas' urbanizadas. Las llamadas urbanizaciones, situadas en los suburbios (condominios en América Latina; 'adosados', en España), cuentan con las comodidades del espacio habitacional moderno, pero carecen de la vida cultural asociada a la ciudad.

Los pueblos no han quedado libres de este 'desarrollismo', es decir, de una modernización mal entendida. Los "tres siglos de pulgas y veinte años de asfalto" (vv. 6-8) aluden al paso acelerado que el campo español ha experimentado desde el sistema de vida tradicional hasta la vida postmoderna. Es un lugar común decir que España ha pasado de la premodernidad a la postmodernidad sin haber transitado -o habiéndolo hecho rápidamentepor la modernidad. Las estrechas calles de los pueblos han sido asfaltadas y, en lugar de quedar peatonalizadas, para uso exclusivo del transeúnte, han sido organizadas bajo el esquema aceracarretera, con un ínfimo y estrecho espacio otorgado a los transeúntes. En otras palabras, la organización del espacio público en red y flujo (en detrimento de la ciudadanía), ha llegado a invadir a las urbanizaciones e, incluso, a los pueblos tradicionales. La voz enunciativa no se engaña ante estos últimos: tan negativo es el pasado de miseria e insalubridad (simbolizado por los 'tres siglos de pulgas') de la vida premoderna como el presente impersonal (simbolizado por el asfalto y las estrechas aceras).

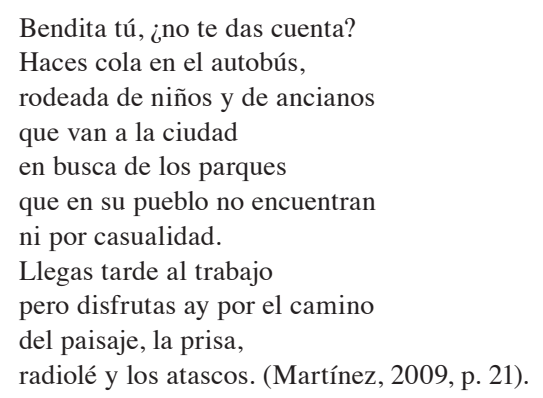

En la segunda estrofa se ofrece el desplazamiento semántico del tópico del Beatus ille: el habitante del suburbio, ubicado al lado de un pueblo tradicional, solo llega a su residencia a dormir (una actividad que perfectamente podría haber realizado en un apartamento urbano). No solo 'debe' regresar a la ciudad para trabajar sino también para encontrar y disfrutar de aquellos placeres supuestamente 'rurales' que, paradójicamente, estaba buscando a la hora de trasladarse a la urbanización. Nos referimos a caminar y a ver 'verde', actividades disponibles en los parques urbanos. 
No se desprende ningún beneficio de la vida en el suburbio: sus habitantes llegan tarde al trabajo (que se encuentra ubicado en la ciudad) como consecuencia de las presas o atascos y, paradójicamente, otro de los pocos momentos que tienen para disfrutar de la naturaleza no lo ofrece la misma urbanización, en última instancia un 'enclave' urbano en el campo (como los turísticos), sino el trayecto que realiza en automóvil, en el que podrá observar -desde el asiento- el lejano paisaje rural.

La ironía máxima se da a partir del hecho de que se termina buscando un pedazo de naturaleza ('domesticada', 'culturalizada') en la ciudad. La interpelación "Bendita tú, ¿no te das cuenta?" (v. 12) representa una sacudida dirigida al sujeto alienado y, como enunciado irónico, transmite el siguiente significado implícito, que podríamos formular en los siguientes términos, si quisiéramos obtener el significado explícito: 'Insensata tú, mujer de Dios, ¿no te das cuenta del absurdo de comprar una casa en un suburbio si tu deseo de trasladarte a vivir a este último consistía en disfrutar de la naturaleza?'.

\section{Conclusiones}

Los símbolos, las metáforas y los tópicos son mecanismos que guardan la memoria de una cultura. Son resignificados, resemantizados o actualizados. En particular, el tópico del Beatus ille, contenido en el "Épodo II", de Épodos (1986), de Horacio -y que obtiene su nombre de los dos primeros versos de este poema-, no ha dejado de ser objeto de atención a lo largo de sus dos milenios de existencia, tanto en sus numerosas reescrituras como en la crítica literaria, al ser objeto de constantes acercamientos analíticos e interpretativos.

¿Por qué motivo se puede considerar el Beatus ille un universal tópico? ¿Qué constantes del inconsciente pretende expresar? Ante todo, la búsqueda que todo ser humano tiene de un refugio sereno, alejado de los conflictos sociales y de la vida compleja y problemática de la civilización urbana. Frente a la conciencia de la banalidad o la impostura que ronda alrededor de muchas preocupaciones sociales, se erige un ideal de plenitud individual que cuenta con unas coordenadas espaciales concretas, llámese aldea, campo, espacio rural, hacienda... La complejidad de la vida cotidiana de la modernidad tardía (léase postmodernidad) ha motivado, asimismo, la actualización del tópico en la producción de diversos escritores.

En este sentido, este tópico ha quedado revitalizado en las últimas generaciones poéticas. Ha sido objeto de homenaje en "De Vita Beata", de Jaime Gil de Biedma, "Un tema de Horacio", de Luis Antonio de Villena y "Beata illa", de Erika Martínez, poemas analizados en el presente artículo. En algún caso, se procede en la actualización a una resemantización en clave metaliteraria. El sujeto que se retira de la vida conflictiva de la ciudad (sociedad) para adoptar el aurea mediocritas de la vida campestre es un intelectual o un escritor. Es lo que ocurre con "De Vita Beata", de Jaime Gil de Biedma. Se adopta una actitud ética: es preferible el alejamiento de los conflictos y la aceptación de un estilo de vida mediocre, antes que reincidir en un compromiso intelectual o político infructuoso. En otro caso, se procede a una reescritura epicúrea, como en "Un tema de Horacio", de Luis Antonio de Villena. Núcleo semántico de este poema es la búsqueda del placer momentáneo de los sentidos, programa que solo puede encontrar en el campo el sujeto que carece de obligaciones sociales. Pero no solo se expresa a través de las actualizaciones de este tópico un desengaño hacia la función social del escritor o una búsqueda epicúrea del placer. Además, como ocurre en "Beata illa", de Erika 
Martínez, se plantea una crítica desencantada del consumismo de la sociedad del bienestar del capitalismo tardío, a través de la crítica de los falsos paraísos de las urbanizaciones.

El Beatus ille no es un tópico que represente los ideales utópicos de la juventud, sino la realidad desencantada de la vida madura. Es más deseable la rutina de una vida plácida y sencilla que los combates infructuosos del espacio público. Y esta crítica se realiza desde la ironía. Hemos visto en el presente artículo que, si bien el tono irónico se pierde en las reescrituras del tópico realizadas durante la época del Clasicismo, se vuelve a emplear en las postmodernas de las últimas generaciones de la poesía española.

En Horacio, irónicamente se procede a la defensa del otium, frente al negotium, en voz de Alfio. ¿Qué ocurre con la dicotomía otium-negotium ${ }^{8}$ en los ejemplos analizados? En Gil de Biedma, más que hacia el ocio, la actitud del hablante enunciativo se orienta a una renuncia del negotium cercana al nihilismo; en Luis Antonio de Villena, el hablante busca un ocio entendido como entrega al placer de los sentidos; en Erika Martínez, por último, se procede a realizar una crítica del ocio postmoderno.

\section{Bibliografía}

Agrait, G. (1971). El 'Beatus ille’ en la poesía del Siglo de Oro. Río Piedra: Universidad de Puerto Rico.

Albornoz, V. D. (2014). La vida urbana y la vida rural según Horacio. El discurso irónico y proléptico en el épodo 2. Argus-a, 4(14), 1-21.

Augé, M. (1996). Los “no-lugares". Espacios del anonimato. Una antropología de la sobremodernidad. Barcelona: Gedisa.

Barrenechea, A. M. (2017). Inversión del tópico del Beatus Ille en La ciudad ausente. Landa, 5(2), 180-196.

Cacho Casal, R. (2003). La poesía burlesca de Quevedo y sus modelos italianos. Santiago de Compostela: Universidad de Santiago de Compostela.

Carrasco, F. (1993). Transformaciones de un modelo textual: el Beatus ille en las Soledades de Góngora. En I. Arellano Ayuso, C. Pinillos Salvador M. Vitse y F. Serralta (Coords.), Studia Aurea. Actas del III Congreso de la AISO (Toulouse, 1993) (Vol. 1, pp. 287298). España: Universidad de Navarra, GRISO (Grupo de Investigación Siglo de Oro).

Conte, G. B. (1994). Latin Literature. A History. Baltimore: The John Hopkins University Press.

Curtius, E. R. (1976). Literatura europea y Edad media latina. México: Fondo de Cultura Económica.

Cuvardic García, D. (1998). La desmitificación nostálgica neofabuladora de la nueva narrativa española en Beatus ille, de Antonio Muñoz Molina. (Tesis de Maestría). Universidad de Costa Rica.

8 En Hernández de la Fuente (2012) se puede encontrar una discusión sobre la semántica del término griego scholé y de su contrapartida latina otium. 
Cuvardic García, D. y Pérez Parejo. R. (2019). El tópico lírico de las hojas secas en la poesía latinoamericana del siglo XX. Revista de Filología y Lingüística de la Universidad de Costa Rica, 45(1), 85-100. doi: https://doi.org/10.15517/rfl.v45i1.36672

De la Vega, G. (2001). Égloga II. En Obra poética y textos en prosa. (B. Morros, ed.). Madrid: Crítica.

De León, F. L. (1999). Canción a la vida solitaria. En P. Jauralde Pou (Ed.), Antología de la poesía española del Siglo de Oro (Siglos XVI-XVII) (pp. 123-127). Madrid: Editorial Espasa-Calpe.

De Vega, G. (1987). El villano en su rincón. (J. M. Marín Martínez, ed.). Madrid: Cátedra.

De Vega, G. (2010). Pastores de Belén: prosas y versos divinos. Madrid: Cátedra.

De Villena, L. A. (1983). Un tema de Horacio. Poesía. 1970-1982. Madrid: Editorial Visor.

De Villena, L. A. (2004). Un tema de Horacio. En J. A. González Iglesias (Ed.), Alejandrías [Antología, 1970-2003] (pp. 73-74). Sevilla: Editorial Renacimiento.

Debicki, A. (1997). Historia de la poesía española del siglo XX. Desde la Modernidad hasta el presente. Madrid: Gredos.

El último de la fila. (1990). “Beatus Ille”. En Nuevo pequeño catálogo de seres y estares. [Álbum musical]. EMI.

Febles, J. (2016). “Un pueblo”: menosprecio de corte y alabanza de aldea en la poesía de Agustín Acosta. Repertorio Americano, (26), 133-147. doi: https://doi.org/10.15359/ra.1-26.8

Gil de Biedma, J. (1991). De Vita Beata. En Las personas del verbo (p. 173). Barcelona: Seix Barral.

Gimferrer, P. (2000). Poemas (1962-1969). Poesía castellana completa. (J. Barella, ed.). Madrid: Visor.

González Arce, T. (2005). El aprendizaje de la memoria. La experiencia hermenéutica en la obra de Antonio Muñoz Molina. Guadalajara: Universidad de Guadalajara.

Guevara, A. de (1984). Menosprecio de Corte y Alabanza de Aldea. Arte de Marear. (A. Rallo Gruss, ed.). Madrid: Cátedra.

Guillén, C. (2005). Entre lo uno y lo diverso. Introducción a la literatura comparada. Barcelona, Tusquets Ediciones.

Guillén, J. (1975). Beato Sillón. En V. Gaos (Ed.), Antología del grupo poético de 1927 (p. 79 ). Madrid: Cátedra.

Hardy, T. (2002). Lejos del mundanal ruido. Barcelona: Alba editorial.

Hernández de la Fuente, D. (2012). La escuela del ocio: tiempo libre y filosofía antigua. Cuadernos Hispanoamericanos, (747), 77-100.

Horacio. (1984). Odas. Épodos. Arte poética. [Introducción, traducción y notas de Alfonso Cuatrecasas]. Barcelona: Editorial Bruguera.

Latorre Madrid, M. A. (2003). La narrativa de Antonio Muñoz Molina. Beatus Ille como metanovela. Málaga: Universidad de Málaga.

López Martínez, M. I. (2007). El tópico literario: teoría y crítica. Madrid: Arco libros. 
Lotman, I. (2000). El símbolo en el sistema de la cultura. En La semiosfera. (Vol. 3, pp. 143156). Madrid: Cátedra.

Marqués de Santillana. (1961). La comedieta de Ponça. En G. Díaz-Plaja (Dir.). Antología mayor de la literatura española. Neoclasicismo, romanticismo, realismo (Siglos $X-X V)$ (Vol. 1, pp. 846-850). Barcelona, Editorial Labor.

Martínez, E. (2009). Beata illa. En Color carne (p. 21). Valencia: Pre-Textos.

Mercer, S., Rudin, S., Shyamalan, M. N. (Productores) y Shyamalan M. N. (Director). (2004). La aldea (The Village) [Película]. Estados Unidos: Blinding Edge Pictures.

Miranda Hevia, G. A. (1975). El problema de la enunciación del yo lírico en el "Beatus Ille", de Quinto Horacio Flaco. Revista de Filología y Lingüística de la Universidad de Costa Rica, 1(2), 81-91. doi: https://doi.org/10.15517/rfl.vli2.15033

Muñoz Molina, A. (1986). Beatus ille. Barcelona: Seix Barral.

Pérez Parejo, R. (2007). Metapoesía y ficción: claves de una renovación poética (Generación de los 50-Novísimos). Madrid: Visor.

Prieto de Paula, A. (1996). Musa del 68: Claves de una generación poética. Madrid: Hiperión.

Quance, R. (1987). Writing Posthumously: Jaime Gil de Biedma. Anales de la literatura española contemporánea, 12(3), 291-309.

Ramajo Caño, A. (1994). El carácter proemial de la Oda Primera de Fray Luis. Romanische Forschung, 106, 84-117.

Sartre, J. P. (1990). ¿Qué es la literatura? Buenos Aires, Losada.

Schiller, F. (1995). Sobre poesía ingenua y sentimental. (P. Aullón de Haro, ed.). Madrid: Editorial Verbum.

Thoreau, H. D. (1854). Walden, or Life in the woods. Boston: Ticknor and Fields.

Torre, E. (1999). La traducción del Épodo II de Horacio (Beatus Ille). Revista de Traducción e Interpretación, (1), 1-14.

Virgilio. (2010). Geórgicas. Madrid: Editorial Gredos. 
